\title{
Micellar Effect on Photoinduced Electron Transfer Reactions of Ruthenium(II) Polypyridyl Complexes with Quinones: Effect of CTAB
}

\author{
Thangadurai Sumitha Celin, George Allen Gnana Raj \\ Department of Chemistry \& Research Centre, Scott Christian College (Autonomous), Nagercoil, India \\ Email: allengraj@gmail.com
}

How to cite this paper: Celin, T.S. and Raj, G.A.G. (2019) Micellar Effect on Photoinduced Electron Transfer Reactions of Ruthenium(II) Polypyridyl Complexes with Quinones: Effect of CTAB. Open Journal of Inorganic Chemistry, 9, 1-10.

https://doi.org/10.4236/ojic.2019.91001

Received: December 13, 2018

Accepted: January 27, 2019

Published: January 30, 2019

Copyright $\odot 2019$ by author(s) and Scientific Research Publishing Inc. This work is licensed under the Creative Commons Attribution-NonCommercial International License (CC BY-NC 4.0). http://creativecommons.org/licenses/by-nc/4.0/

\begin{abstract}
Photoinduced electron transfer reaction between the excited state ruthenium (II) polypyridyl complexes and quinones has been investigated in cetyltrimethylammonium bromide using luminescent quenching techniques. The complexes have the absorption and emission maximum in the range $452-468 \mathrm{~nm}$ and $594-617 \mathrm{~nm}$ respectively. The static nature of quenching is confirmed from the ground state absorption studies. The association constants for the complexes with quinones are calculated from the Benesi-Hildebrand plots using absorption spectral data. The value of quenching rate constant $\left(k_{q}\right)$ is highly sensitive to the nature of the ligand and the quencher, the medium, structure and size of the quenchers. Compared to the aqueous medium, the electron transfer rate is altered in $\mathrm{CTAB}$ medium. The oxidative nature of the quenching is confirmed by the formation of $\mathrm{Ru}^{3+}$ ion and quinone anion radical.
\end{abstract}

\section{Keywords \\ Quenching, Stern-Volmer Plot, Static Quenching, \\ $\mathrm{Ru}(\mathrm{II})$ Polypyridyl Complex}

\section{Introduction}

Luminescence quenching is a very important technique to get adequate information about the structure, properties and reactions of luminescent molecules. Quenching is an important process by which the luminescence intensity of the luminophore is reduced by various processes like molecular rearrangements, ex- 
cited state reactions, ground-state complex formation and collisional quenching [1]. The photochemistry and photophysics of transition metal complexes having $\mathrm{d}^{6}$ electronic configuration, have attracted the chemists in the field of solar energy conversion [2], and biomolecular sensing [3] so as to characterize the microheterogeneous environments, due to their favorable photophysical properties, excited state reactivities and chemical stability [4]. Of these, $\mathrm{Ru}(\mathrm{II})$ polypyridyl complexes have been investigated to a greater extent. The photoinduced electron transfer reactions of $\left[\mathrm{Ru}(\mathrm{NN})_{3}\right]^{2+}$ (where $\mathrm{NN}^{\prime}=2,2^{\prime}$-bipyridine and its alkyl derivatives) with several quinones have been studied. These reactions are highly influenced by the change in the structure of the ligands of the polypyridyl complex as well as the quenchers. There is a decrease in the quenching rate constant with bulkiness of the ligand and the quencher. This has been explained in terms of the electron transfer distance between the luminophore and the quencher [5]. The introduction of electron releasing and electron with-drawing groups in the 4,4'-position of 2,2'-bipyridine alters the polar as well as the steric effect of the reactants. The hydrophobicity is also affected.

Quinones are important class of organic compounds used in various electrochemical processes during biological energy storage and storage. They have a good redox behavior and act as an efficient electron acceptor. Many biological processes like respiration operate only due to the active quinone species [6]. Attempts have been made in recent years to design and synthesize molecules that mimic natural biological processes and light driven process like photosystem II [7] [8] [9] [10] [11]. Many biological membrane and membrane protein were used as simple model systems [12]. One of the typical such membranes is the micelles. Micelles are organized assemblies of surfactants in organic solvents. These surfactants are active at the interphase and they possess both hydrophilic and hydrophobic characteristics in the same molecule. The solubility of the hydrophobic compound in an aqueous medium can be dramatically enhanced by the addition of surfactant. The structure of micelle (i.e. shape, size, aggregation number) depends on the architecture of the surfactant molecule. Those molecules accommodated in molecular assemblies have greater degree of organization than those in the homogeneous medium. Thus these aqueous micelle bound systems are an attractive alternative to highly toxic and expensive organic solvents.

A well known surfactant is cetyltrimethylammonium bromide. A series of surfactant ruthenium (II) bipridyl derivatives have been reported previously [13]. Ruthenium (II) polypyridyl complexes have been extensively studied in micellar media. Their photophysical properties like absorption maxima, emission maxima, quantum yield, excited state lifetime vary enormously with the nature of the surfactant molecule. Electrostatic and hydrophobic interactions between micelles and reactants will alter the rate as well as the kinetics of the reaction between the micelle and the reactant. The present study deals with the electron transfer reactions of $\left[\mathrm{Ru}(\mathrm{NN})_{3}\right]^{2+}$ complexes with quinones in CTAB 
media. The results observed in the aqueous and CTAB media are discussed here.

\section{Experimental}

\subsection{Materials}

The three $\left[\mathrm{Ru}(\mathrm{NN})_{3}\right]^{2+}$ complexes $[\mathrm{NN}=$ bipyridine (bpy),

4,4'-dimethyl-2,2'-bipyridine (dmbpy), 4,4'-di-t-butyl, 2,2'-bipyridine (dtbpy)] were synthesized from known procedures [14] [15] byreacting $\mathrm{RuCl}_{3} \cdot 3 \mathrm{H}_{2} \mathrm{O}(1 \mathrm{mM})$ with the corresponding ligands $(3 \mathrm{mM})$ dissolved in $20 \mathrm{ml}$ of ethylene glycol and refluxing for 4 hours. The solution was then allowed to cool at room temperature and filtered to remove any insoluble impurities. A saturated solution of sodium tetrafluoroborate was then added dropwise into the filtrate until an orange precipitate formed. The product was filtered, washed with cold water and diethyl ether and dried in a vacuum desicator. The product was further purified by recrystallisation from water. The quinones were procured from Sigma Aldrich and were used as such without further purification. The cationic surfactant CTAB was purchased from Merck. The double distilled deionised water was used for the studies.

\subsection{Absorption and Emission Spectral Measurements}

SYSTRONICS 2203 double beam spectrophotometer was used to measure the absorption spectral characteristics. Emission studies were carried out using JASCO-FP-8600 spectrofluorometer. The sample concentrations were maintained at $4 \times 10^{-5} \mathrm{M}$. Quenchers had the concentrations between $4 \times 10^{-6}$ and $2.8 \times$ $10^{-7} \mathrm{M}$. Luminescence measurements and absorption measurements were carried out at room temperature. The sample solutions of same concentration was used for both absorbance and emission measurements. The solutions used for emission studies and excited state lifetime measurements were deaerated for about $30 \mathrm{mts}$ using dry $\mathrm{N}_{2}$ gas purging. Excited state lifetime was measured using laser flash photolysis technique. An applied photophysics SP-Quanta Ray GCR-2(10) Nd YAG laser was used as an excitation source.

The quenching rate constant $\left(k_{q}\right)$ was calculated using Stern-Volmer plot equation,

$$
I_{0} / I=1+k_{q} \tau_{0}[Q]
$$

where $I_{0}$ and $I$ are the emission intensities in the absence and presence of quencher respectively and $\tau_{0}$ is the emission lifetime of the $\mathrm{Ru}(\mathrm{II})$ complex in the absence of the quencher.

\section{Results and Discussion}

The structure of the ligands and the quenchers used in the present study are shown in Figure 1.

The photophysical properties like absorption maxima, emission maxima and emission lifetime of the $\left[\mathrm{Ru}(\mathrm{NN})_{3}\right]^{2+}$ complexes are depicted in Table 1. The absorption maxima of the complexes are in the range of $448 \mathrm{~nm}$ to $458 \mathrm{~nm}$ in 

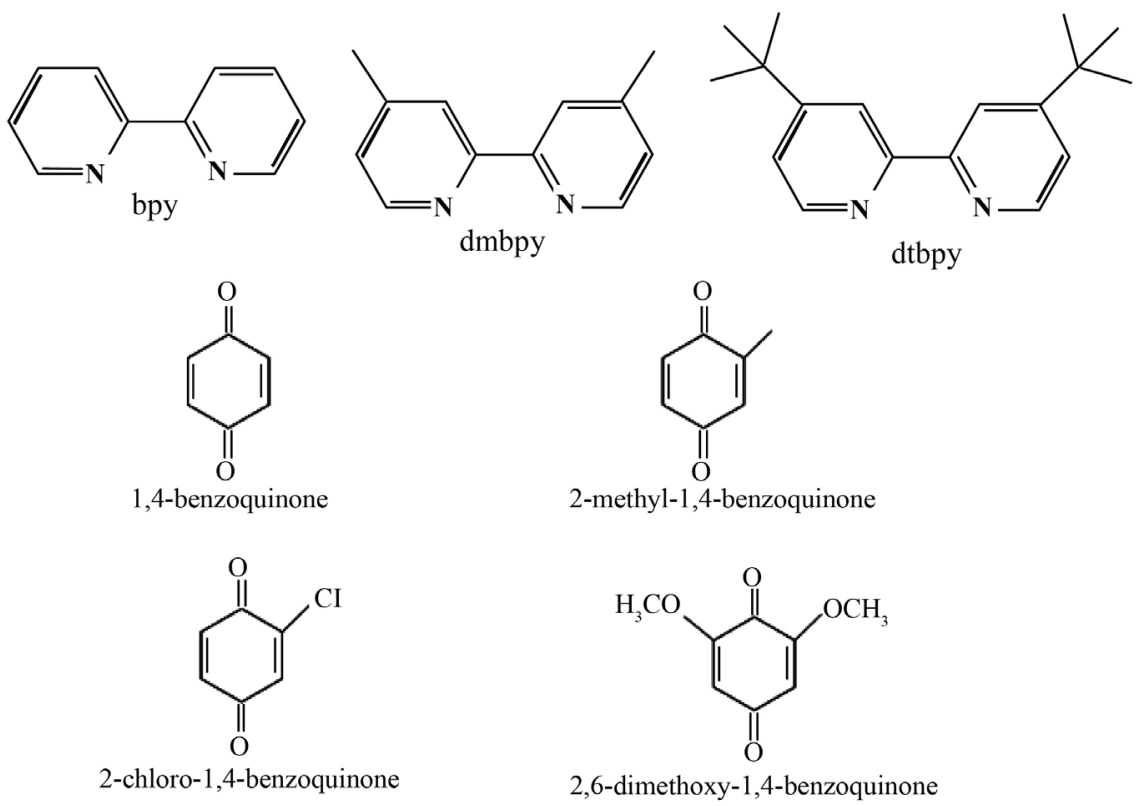

Figure 1. Structure of the ligands and the quinones.

Table 1. Absorption, emission spectral data and excited state lifetime of $\left[\mathrm{Ru}(\mathrm{NN})_{3}\right]^{2+}$ complex with quinones in CTAB medium.

\begin{tabular}{cccccccc}
\hline \multirow{2}{*}{ Complex } & \multicolumn{2}{c}{$\begin{array}{c}\text { Absorption } \\
\text { maximum }(\mathrm{nm})\end{array}$} & \multicolumn{2}{c}{$\begin{array}{c}\text { Emission maximum, } \\
(\mathrm{nm})\end{array}$} & \multicolumn{2}{c}{ Life time $\boldsymbol{\tau}(\mathrm{ns})$} \\
\cline { 2 - 8 } & $\mathrm{aq}$ & $\mathrm{CTAB}$ & aq & CTAB & aq & CTAB \\
\hline$\left[\mathrm{Ru}(\mathrm{bpy})_{3}\right]^{2+}$ & 448 & 452 & 596 & 594 & 650 & 387 \\
{$\left[\mathrm{Ru}(\mathrm{dmbpy})_{3}\right]^{2+}$} & 458 & 459 & 605 & 606 & 360 & 250 \\
{$\left[\mathrm{Ru}(\mathrm{dtbpy})_{3}\right]^{2+}$} & 457 & 468 & 625 & 617 & 510 & 290 \\
\hline
\end{tabular}

aqueous medium. The emission maxima range from $452 \mathrm{~nm}$ to $461 \mathrm{~nm}$. All the three $\mathrm{Ru}$ (II) complexes show a strong ligand centred (LC) $\pi$ - $\pi^{*}$ transition in the region $260 \mathrm{~nm}$ to $280 \mathrm{~nm}$ region and a low energy absorption in the 452 to $461 \mathrm{~nm}$ region assigned to the $\mathrm{d}_{\pi-\pi^{*}}$ MLCT transition. In $\left[\mathrm{Ru}(\mathrm{bpy})_{3}\right]^{2+}$ complex, the MLCT absorption maximum is at $448 \mathrm{~nm}$ in the aqueous medium. There is a bathochromic shift in the absorption maximum to the tune to $10 \mathrm{~nm}$ due to the introduction of dmbpy, dtbpy ligands in the aqueous medium. The change in medium from homogeneous to microheterogeneous medium also alters the photophysical properties.

These data show that micelles lower the energy level of ${ }^{3}$ MLCT states, thereby they stabilize them relative to the $\mathrm{d}$ - $\mathrm{d}$ state. The absorption spectrum is recorded in water-acetonitrile medium (9:1 v/v). Figure 2 displays the absorption spectrum of $\left[\mathrm{Ru}(\mathrm{NN})_{3}\right]^{2+}$ complex in CTAB medium. There is a slight change in the emission spectrum of the $\mathrm{Ru}$ (II) complexes in $\mathrm{CTAB}$ medium compared to that of the aqueous medium. These observations substantiate the importance of hydrophobic interactions between the ligands of the probe and the cationic micelle. These hydrophobic interactions affect the columbic repulsion and thereby 


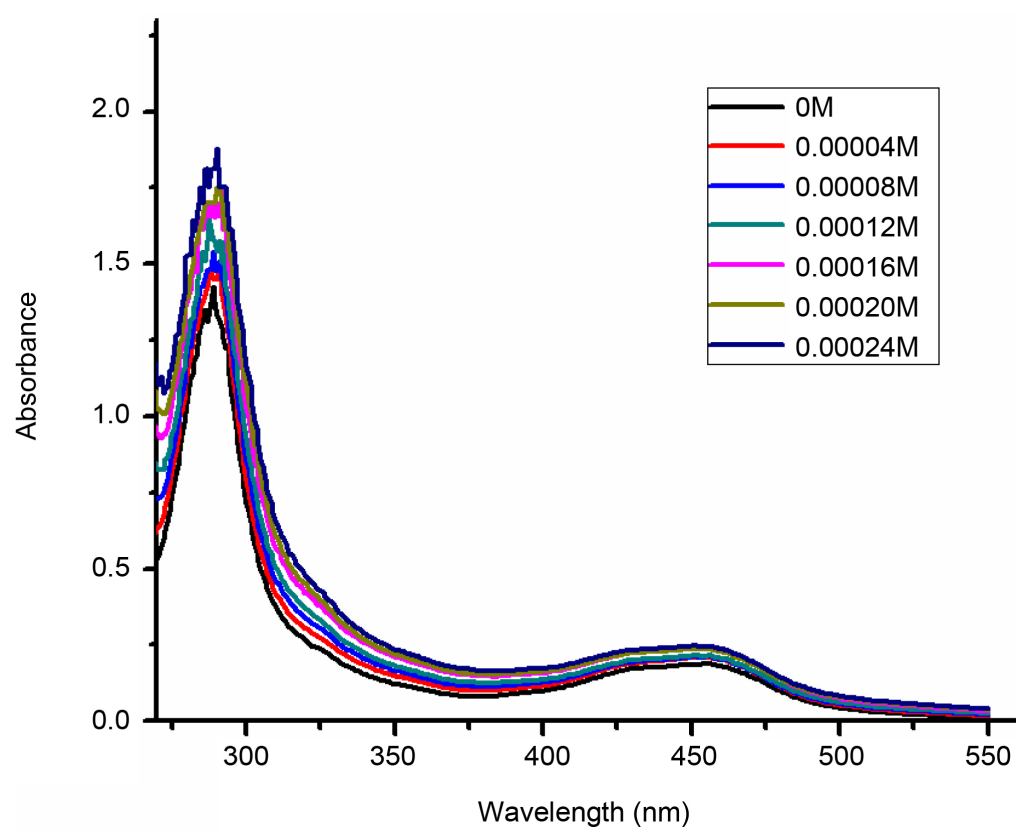

Figure 2. Absorption spectrum of $\left[\mathrm{Ru}(\mathrm{bpy})_{3}\right]^{2+}$ with incremental concentration of 1,4-benzoquinone in CTAB medium.

bring the ruthenium (II) complexes close to the cationic micelle. The results show the importance of hydrophobic effect over the electrostatic forces.

\subsection{Oxidative Quenching of $\left[\mathrm{Ru}(\mathrm{NN})_{3}\right]^{2+}$ Complexes with Quinones in the Presence of Cationic Surfactant}

The photoinduced ET reactions of $\left[\mathrm{Ru}(\mathrm{NN})_{3}\right]^{2+}$ complexes with quinones in presence of cationic surfactant $\mathrm{CTAB}$ has been studied using luminescence technique. The absorption spectral studies of $\left[\mathrm{Ru}(\mathrm{bpy})_{3}\right]^{2+},\left[\mathrm{Ru}(\mathrm{dmbpy})_{3}\right]^{2+},\left[\mathrm{Ru}(\mathrm{dtbpy})_{3}\right]^{2+}$ complexes with the incremental addition of para quinones are performed in order to check the formation of ground state complex in aqueous and CTAB medium. There is a shift in the MLCT absorption maximum of these complexes with the addition of quinone derivatives indicating that there is ground state complex formation and this concluded the static nature of quenching in the present experimental condition.

The absorption spectral studies of $\left[\mathrm{Ru}(\mathrm{bpy})_{3}\right]^{2+}$ complexes with incremental concentration of 1,4-benzoquinone shows a slight shift in the MLCT absorption maximum, confirming the formation of ground state complex (Figure 2). The emission spectrum of $\left[\mathrm{Ru}(\mathrm{dmbpy})_{3}\right]^{2+}$ with incremental concentration of 2-methyl-1,4-benzoquinone in CTAM medium is shown in Figure 3. The association of these complexes with quinones may be due to static quenching. The association constant $\left(\mathrm{K}_{\mathrm{a}}\right)$ of $\left[\mathrm{Ru}(\mathrm{NN})_{3}\right]^{2+}$ complexes with quinones calculated using Benesi-Hildebrand equation is given in Table 2. The obtained $\mathrm{K}_{\mathrm{a}}$ values are in the range of $10^{3}-10^{5} \mathrm{M}^{-1}$. The Benesi Hildebrand plots for the absorption spectral data of $\left[\mathrm{Ru}(\mathrm{bpy})_{3}\right]^{2+}$ complex with quinones are displayed in Figure 4. These photoluminescence studies show that the association of $\left[\mathrm{Ru}(\mathrm{NN})_{3}\right]^{2+}$ 


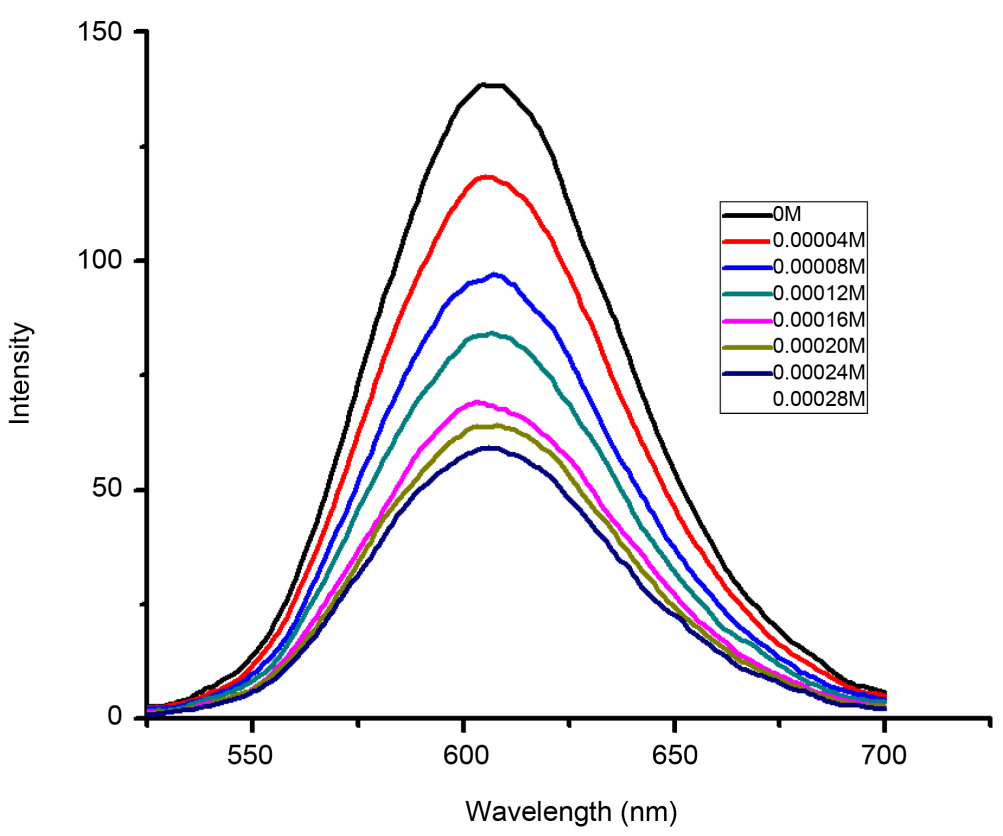

Figure 3. Emission spectrum of $\left[\mathrm{Ru}(\mathrm{dmbpy})_{3}\right]^{2+}$ with incremental concentration of 2-methyl-1,4-benzoquinone in CTAB medium.

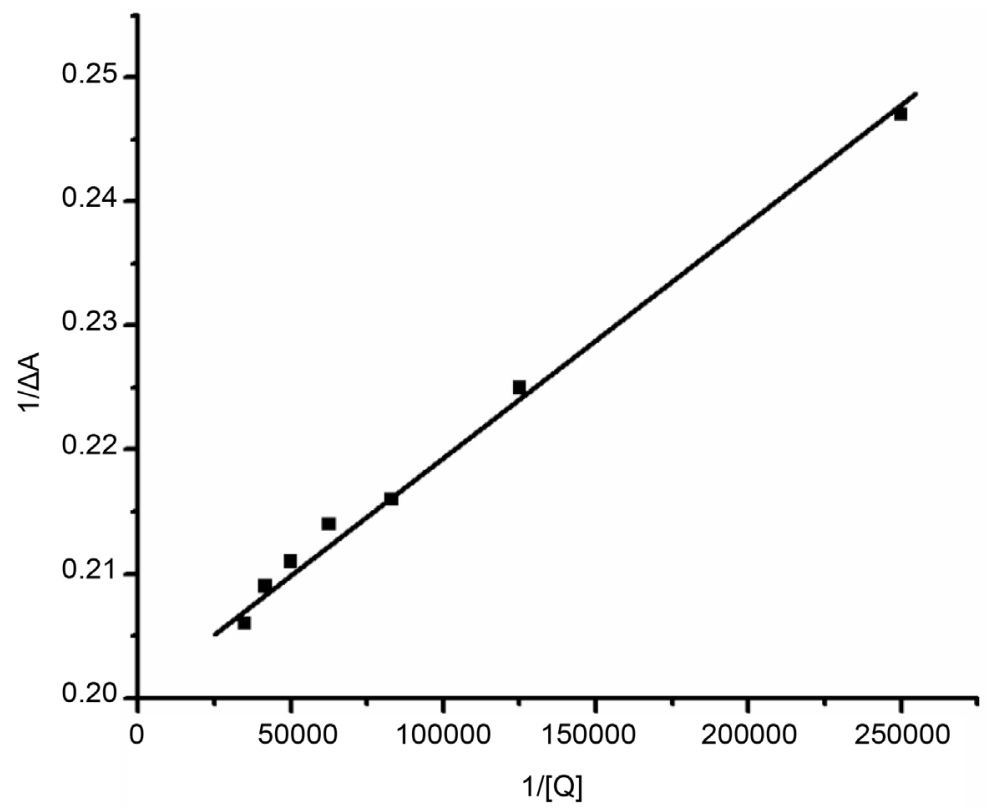

Figure 4. The Benesi-Hildebrand plot from the absorption spectral data of * $\left[\mathrm{Ru}(\mathrm{bpy})_{3}\right]^{2+}$ with 1,4-benzoquinone in CTAB media.

Table 2. Association constant $\mathrm{K}_{\mathrm{a}}\left(\mathrm{M}^{-1}\right)$ and first order rate constant $\mathrm{k}_{\mathrm{rad}}\left(\mathrm{s}^{-1}\right)$ for the excited state quenching of $\left[\mathrm{Ru}(\mathrm{NN})_{3}\right]^{2+}$ complexes with quinones in CTAB media.

\begin{tabular}{ccccc}
\hline \multirow{2}{*}{ Quencher } & \multicolumn{2}{c}{$\left[\mathrm{Ru}(\mathrm{bpy})_{3}\right]^{2+}$} & \multicolumn{2}{c}{$\left[\mathrm{Ru}(\mathrm{dmbpy})_{3}\right]^{2+}$} \\
\cline { 2 - 5 } & $\mathrm{K}_{\mathrm{a}}\left(\mathbf{M}^{-1}\right)$ & $\mathrm{k}_{\mathrm{rad}}\left(\mathrm{s}^{-1}\right)$ & $\mathrm{K}_{\mathrm{a}}\left(\mathbf{M}^{-1}\right)$ & $\mathrm{k}_{\mathrm{rad}}\left(\mathrm{s}^{-1}\right)$ \\
\hline 1,4-benzoquinone & $2.1 \times 10^{4}$ & $4.09 \times 10^{5}$ & $4.71 \times 10^{4}$ & $4.62 \times 10^{5}$ \\
$\begin{array}{c}\text { 2-methyl-1, } \\
\text { 4-benzoquinone }\end{array}$ & $1.17 \times 10^{5}$ & $7.10 \times 10^{5}$ & $1.93 \times 10^{4}$ & $1.15 \times 10^{6}$ \\
\hline
\end{tabular}


complexes and quinones in CTAB media is probably Vander Waals or hydrophobic in nature. The first order rate constant, which is got by the ratio of association constant and quenching rate constant shows that their values lie in the range of $10^{4}$ to $10^{5} \mathrm{M}^{-1}$.

The Stern-Volmer plot for the oxidative quenching of ${ }^{*}\left[\mathrm{Ru}(\mathrm{dmbpy})_{3}\right]^{2+}$ by 1,4-benzoquinone in CTAB medium is shown in Figure 5. The plot reveals that the excited state $\mathrm{Ru}(\mathrm{II})$ complexes are quenched by the quinones. The experimental quenching constant $k_{q}$ technique for the three $\mathrm{Ru}(\mathrm{II})$ complexes with quinone derivatives in cationic micellar medium and aqueous medium are given in Table 3. It is seen that the quenching rate constant values in CTAB medium is higher than the aqueous medium. $\left[\mathrm{Ru}(\mathrm{bpy})_{3}\right]^{2+}$ complex shows a quenching constant of $6.01 \times 10^{9} \mathrm{M}^{-1} \cdot \mathrm{s}^{-1}$ with 2-chloro-1,4-benzoquinone in aqueous medium, whereas in CTAB it has the value of $3.849 \times 10^{10} \mathrm{M}^{-1} \cdot \mathrm{s}^{-1}$. It is seen that different trends are analysed depending on the substituents of the ligands in $\left[\mathrm{Ru}(\mathrm{NN})_{3}\right]^{2+}$ as well as the quencher. The quenching constant value is also influenced by the presence of electron with-drawing or electron-donating group in the parent quencher 1,4-benzoquinone.2-chloro-1,4-benzoquinone is an electron with-drawing substituent and it increases the $k_{q}$ value. The observations lead to a conclusion that electrostatic repulsion between the ligands of the probe and the micelle is compensated by the hydrophobic interaction between the ligands of the probe and the micelle. These results demonstrate the potential application of the micelle bound $\mathrm{Ru}$ complexes as sensors in medical and biological fields.

\subsection{Transient Absorption Spectra}

The oxidative nature of the quenching of ruthenium (II) polypyridyl complexes

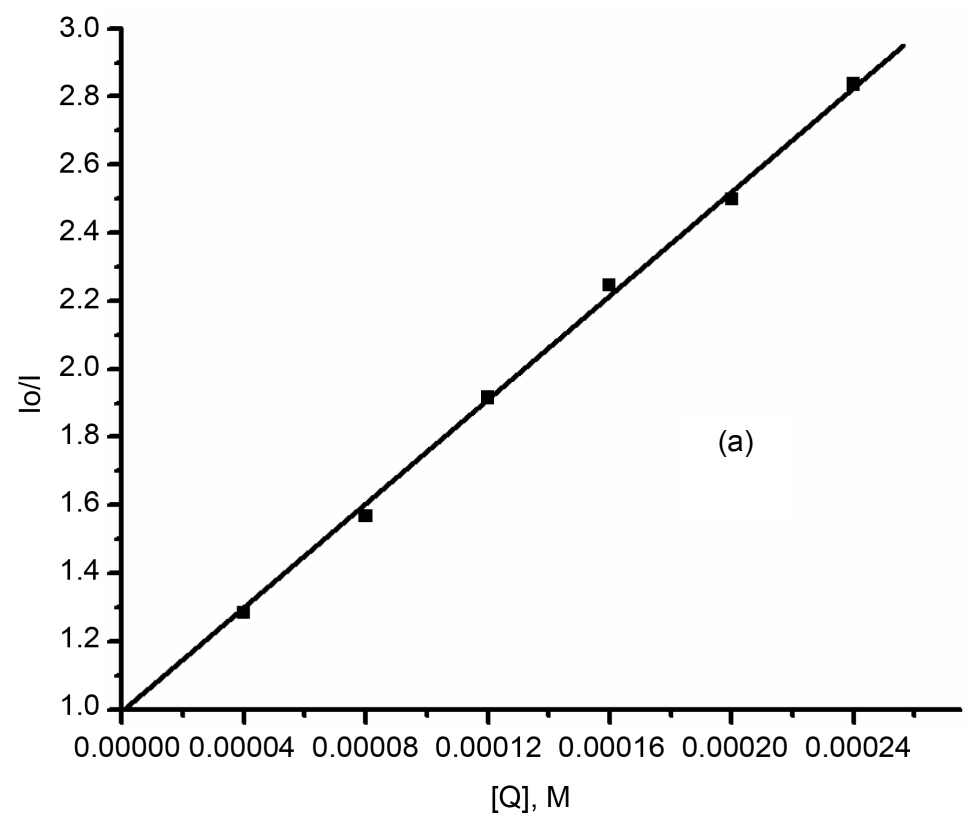

Figure 5. Stern-Volmer plots for the oxidative quenching of (a) ${ }^{\star}\left[\mathrm{Ru}(\mathrm{dmbpy})_{3}\right]^{2+}$ by 1,4 -benzoquinone in $\mathrm{CTAB}$ media. 
Table 3. Luminescence quenching rate constant $\left(k_{\mathrm{q}}\right)$ for the oxidative quenching of $\left[\mathrm{Ru}(\mathrm{NN})_{3}\right]^{2+}$ with quinones in aqueous medium and in CTAB medium at $298 \mathrm{~K}$.

(a)

\begin{tabular}{ccc}
\hline & \multicolumn{2}{c}{$\left[\mathrm{Ru}(\mathrm{bpy})_{3}\right]^{2+}$} \\
\cline { 2 - 3 } Quencher & \multicolumn{2}{c}{$\mathrm{M}^{-1} \cdot \mathrm{s}^{-1}$} \\
\cline { 2 - 3 } & Aqueous & $\mathrm{CTAB}$ \\
\hline 2-chloro 1,4-benzoquinone & $6.01 \times 10^{9}$ & $3.849 \times 10^{10}$ \\
1,4-benzoquinone & $2.461 \times 10^{9}$ & $1.166 \times 10^{10}$ \\
2-methyl-1,4-benzoquinone & $4.071 \times 10^{9}$ & $3.369 \times 10^{10}$ \\
2,6-dimethoxy-1,4-benzoquinone & $1.452 \times 10^{9}$ & $3.318 \times 10^{10}$ \\
\hline
\end{tabular}

(b)

\begin{tabular}{cccc}
\hline \multicolumn{2}{c}{$\left[\mathrm{Ru}(\mathrm{dmbpy})_{3}\right]^{2+}$} & \multicolumn{2}{c}{$\left[\mathrm{Ru}(\mathrm{dtbpy})_{3}\right]^{2+}$} \\
\hline \multicolumn{3}{c}{$\mathrm{M}^{-1} \cdot \mathrm{s}^{-1}$} \\
\hline Aqueous & $\mathrm{CTAB}$ & Aqueous & $\mathrm{CTAB}$ \\
\hline $5.55 \times 10^{9}$ & $3.965 \times 10^{10}$ & $3.11 \times 10^{9}$ & $1.306 \times 10^{10}$ \\
$1.452 \times 10^{10}$ & $4.761 \times 10^{10}$ & $1.38 \times 10^{10}$ & $5.959 \times 10^{10}$ \\
$1.563 \times 10^{10}$ & $2.237 \times 10^{10}$ & $2.001 \times 10^{9}$ & $2.76 \times 10^{10}$ \\
$1.35 \times 10^{9}$ & $7.865 \times 10^{10}$ & $4.484 \times 10^{9}$ & $3.02 \times 10^{10}$ \\
\hline
\end{tabular}

is confirmed by the transient absorption spectrum. Argon bubbled CTAB (0.04 M) solution of $\mathrm{Ru}(\mathrm{II})$ complex were excited at $355 \mathrm{~nm}$ under laser flash photolysis. The transient absorption spectrum of ${ }^{*}\left[\mathrm{Ru}(\mathrm{dmbpy})_{3}\right]^{2+}$ in the presence of 0.001 M 2,6-ditertiary butyl-1,4-benzoquinone in CTABat $1 \mu$ s, after $355 \mathrm{~nm}$ laser flash photolysis is shown in Figure 6. It consists of bleach around $450 \mathrm{~nm}$ and a positive absorption with a maximum centered at $370 \mathrm{~nm}$. This is due to the substituted bipyridyl anion radical. The bleach around $450 \mathrm{~nm}$ is due to the loss of ground state absorption $\mathrm{d}_{\pi-\pi^{*}}$ (MLCT) transition. The bleach around 600 - 700 $\mathrm{nm}$ corresponds to the relaxation of excited state to the ground state. The band at $643 \mathrm{~nm}$ confirms the formation of $\mathrm{Ru}^{3+}$ species as transient. Thus the formation of $\mathrm{Ru}^{3+}$ species and quinone anion radical as transient species confirms the oxidative quenching of the complex.

\section{Conclusion}

The present study clearly establishes the effect of cationic micelle on the quenching of $\left[\mathrm{Ru}(\mathrm{bpy})_{3}\right]^{2+},\left[\mathrm{Ru}(\mathrm{dmbpy})_{3}\right]^{2+}$ and $\left[\mathrm{Ru}(\mathrm{dtbpy})_{3}\right]^{2+}$ with para-quinones. Absorption spectral data show that the quenching is static in nature. The value of quenching rate constant is sensitive to the medium, nature and structure of the ligand and the quenchers used, the electron transfer distance between the luminophore and quencher. The detection of $\mathrm{Ru}^{3+}$ species and formation of quinone anion radical confirms the oxidation nature and electron transfer nature of quenching. Thus the change in medium from homogeneous to microheterogeneous strongly influences the $k_{q}$ due to the presence of hydrophobic interaction. 


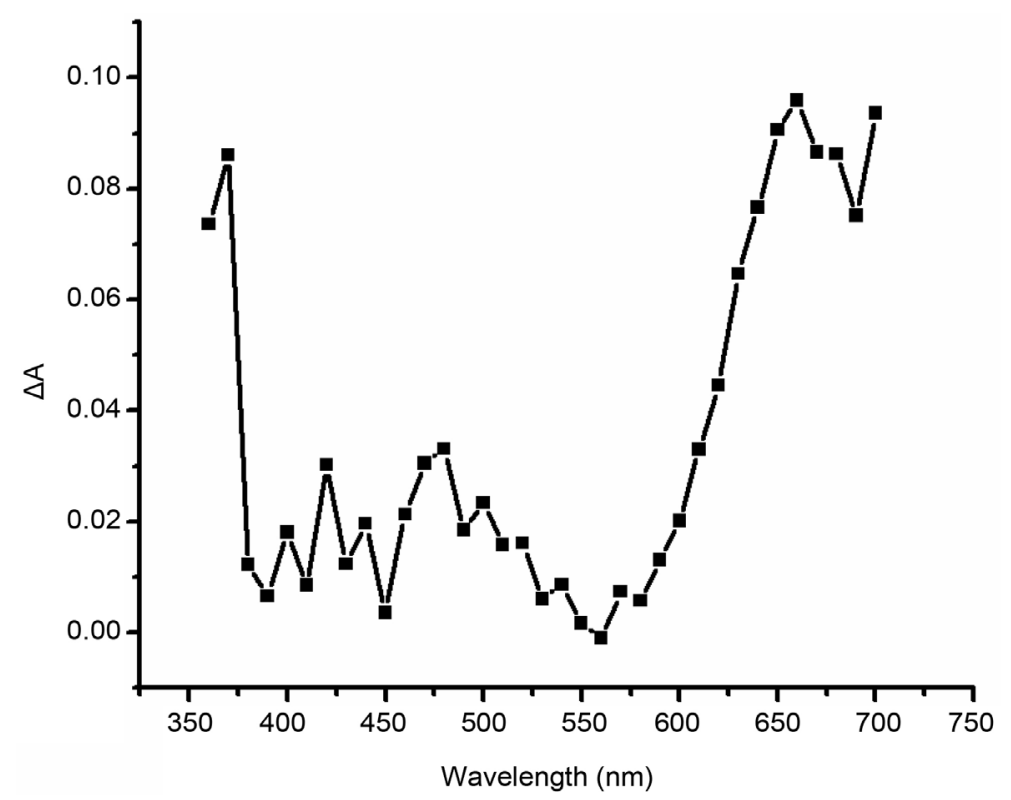

Figure 6. Transient absorption spectra of ${ }^{\star}\left[\operatorname{Ru}(\mathrm{dmbpy})_{3}\right]^{2+}$ at $1 \mu \mathrm{s}$, after 355 $\mathrm{nm}$ laser flash photolysis in the presence of $0.001 \mathrm{M}$ 2,6-ditertiary butyl-1,4-benzoquinone in CTAB.

\section{Conflicts of Interest}

The authors declare no conflicts of interest regarding the publication of this paper.

\section{References}

[1] Daniel, S. and Allen Gnana Raj, G. (2017) Importance of Hydrophobic Interactions on the Luminescence Quenching of Ru(II)-Polypyridyl Complexes with Phenolic Acids and Quercetin in Triton X-100. Journal of Chemistry and Material Research, 6, 37-45.

[2] Sannino, D, Vaiano, V, Ciambelli, P, Zama, I. and Gorni, G. (2013) Evaluation of N719 Amount in $\mathrm{TiO}_{2}$ Films for DSSC by Thermogravimetric Analysis. Journal of Thermal Analysis and Calorimetry, 111, 453-458. https://doi.org/10.1007/s10973-012-2436-x

[3] Vos, J.G. and Kelly, J.M. (2006) Ruthenium Polypyridyl Chemistry; from Basic Research to Applications and Back Again. Dalton Transactions, 41, 4869-4883. https://doi.org/10.1039/b606490f

[4] Sun, Y, Collins, S.N, Joyce, L.E. and Turro, C. (2010) Unusual Photophysical Properties of a Ruthenium(II) Complex Related to $\left[\mathrm{Ru}(\mathrm{bpy})_{2}(\mathrm{dppz})\right]^{2+}$. Inorganic Chemistry, 49, 4257-4262. https://doi.org/10.1021/ic9025365

[5] Rajendran, T., Rajagopal, S., Srinivasan, C. and Ramamorthy, P. (1997) Micellar Effect on the Photoinduced Electron Transfer Reactions of Ruthenium (II)-Polypyridyl Complexes with Phenolate Ion Effect of Cetifltrimethylammonium bromide. Journal of the Chemical Society, Faraday Transactions, 93, 3155-3160. https://doi.org/10.1039/a700039a

[6] Son, E.J., Kim, J.H., Kim, K. and Park, C.B. (2016) Quinones and Its Derivatives for Energy Harvesting and Storage Materials. Journal of Materials Chemistry A, 4, 11179-11202. https://doi.org/10.1039/C6TA03123D 
[7] Manner, V.W. and Meyer, J.M. (2009) Concerted Proton-Electron Transfer in a Ruthenium Terpyridyl-Benzoate System with a Large Separation between the Redox and Basic Sites. Journal of American Chemical Society, 131, 9874-9875. https://doi.org/10.1021/ja902942g

[8] Barber, J. (2008) Crystal Structure of the Oxygen-Evolving Complex of Photosystem II. Inorganic Chemistry, 47, 1700-1710. https://doi.org/10.1021/ic701835r

[9] Shaikh, N., Johansson, O., Anderlund, M.F., Styring, S., Akermark, B., Magnuson, A. and Hammarstrom, L. (2005) Light Induced Manganese Oxidation and Long-Lived

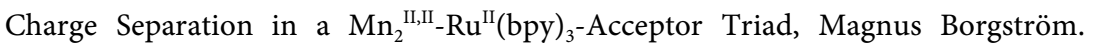
Journal of American Chemical Society, 127, 17504-17515. https://doi.org/10.1021/ja055243b

[10] Iordanova, C.C.N. and Hammes-Schiffer, S. (2003) Proton-Coupled ET in a Model for Tyrosine Oxidation in Photosystem II. Journal of American Chemical Society, 125, 10429-10436. https://doi.org/10.1021/ja035588z

[11] Sun, L.C., Hammerstrom, L., Akermark, B. and Styring, S. (2001) Towards Artificial Photosynthesis: Ruthenium-Manganese Chemistry for Energy Production. Chemical Society Reviews, 30, 36-49. https://doi.org/10.1039/a801490f

[12] Balzani, V. (2001) Electron Transfer in Chemistry. WILEY-VCH Verlag GmbH, Weinheim. https://doi.org/10.1002/9783527618248

[13] el Torki, F.M., Schmehl, R.H. and Reed, W.F. (1989) Photoinduced Electron-Transfer Reactions of Micelle-Forming Surfactant Ruthenium(II) Bipyridyl Derivatives. Journal of Chemical Society, Faraday Transactions, 1, 349-362.

[14] Saha, B. and Stanbury, D.M. (2000) Thermal and Photochemical Reduction of Aqueous Chlorine by Ruthenium(II) Polypyridyl Complexes. Inorganic Chemistry, 39, 1294-1300. https://doi.org/10.1021/ic9910920

[15] Kitamura, N., Kim, H.B., Okano, S. and Tazuke, S. (1989) Photoinduced Electron-Transfer Reactions of Ruthenium(II) Complexes. 1. Reductive Quenching of Excited Tris(2,2'-Bipyridine)Ruthenium(2+) by Aromatic Amines. Journal of Physical Chemistry, 93, 5750-5756. https://doi.org/10.1021/j100352a021 